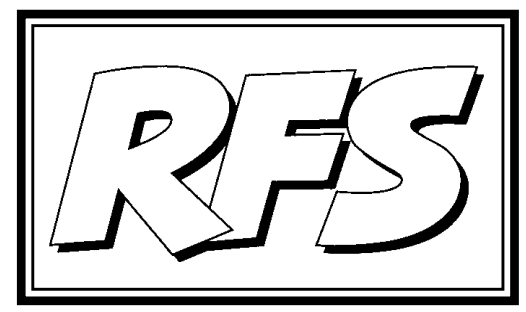

Revista de Fomento Social, 59 (2004), 861-870

\title{
No te dejes vencer por el mal, antes bien, vence al mal con el bien
}

Mensaje de Juan Pablo II para la celebración de la Jornada Mundial de la Paz (1 de enero de 2005)

1. Al comienzo del nuevo año, dirijo una vez más la palabra a los responsables de las Naciones y a todos los hombres y mujeres de buena voluntad, sabedores de lo necesario que es construir la paz en el mundo. He elegido como tema para la Jornada Mundial de la Paz 2005 la exhortación de san Pablo en la Carta a los Romanos: "No te dejes vencer por el mal; antes bien, vence al mal con el bien" $(12,21)$. No se supera el mal con el mal. En efecto, quien obra así, en vez de vencer al mal, se deja vencer por el mal.

La perspectiva indicada por el gran Apóstol subraya una verdad de fondo: la paz es el resultado de una larga y dura batalla, que se gana cuando el bien derrota al mal. Ante el dramático panorama de los violentos enfrentamientos fratricidas que se dan en varias partes del mundo, ante los sufrimientos indecibles e injusticias que producen, la única opción realmente constructiva es detestar el mal con horror y adherirse al bien (cf. Rm 12,9), como sugiere también san Pablo. 
La paz es un bien que se promueve con el bien: es un bien para las personas, las familias, las Naciones de la tierra y para toda la humanidad; pero es un bien que se ha de custodiar y fomentar mediante iniciativas y obras buenas. Se comprende así la gran verdad de otra máxima de Pablo: "Sin devolver a nadie mal por mal" (Rm 12,17). El único modo para salir del círculo vicioso del mal por el mal es seguir la exhortación del Apóstol: "No te dejes vencer por el mal; antes bien, vence al mal con el bien” (Rm 12,21).

\section{El mal, el bien y el amor}

2. La humanidad ha tenido desde sus orígenes la trágica experiencia del mal y ha tratado de descubrir sus raíces y explicar sus causas. El mal no es una fuerza anónima que actúa en el mundo por mecanismos deterministas e impersonales. El mal pasa por la libertad humana. Precisamente esta facultad, que distingue al hombre de los otros seres vivientes de la tierra, está siempre en el centro del drama del mal y lo acompaña. El mal tiene siempre un rostro y un nombre: el rostro y el nombre de los hombres y mujeres que libremente lo eligen. La Sagrada Escritura enseña que en los comienzos de la historia, Adán y Eva se rebelaron contra Dios y Caín mató a su hermano Abel (cf. Gn 3-4). Fueron las primeras decisiones equivocadas, a las que siguieron otras innumerables a lo largo de los siglos. Cada una de ellas conlleva una connotación moral esencial, que implica responsabilidades concretas para el sujeto que las toma e incide en las relaciones fundamentales de la persona con Dios, con los demás y con la creación.

Al buscar los aspectos más profundos, se descubre que el mal, en definitiva, es un trágico huir de las exigencias del amor. ${ }^{1}$ El bien moral, por el contrario, nace del amor, se manifiesta como amor y se orienta al amor. Esto es muy claro para el cristiano, consciente de que la participación en el único Cuerpo místico de Cristo instaura una relación particular no sólo con el Señor, sino también con los hermanos. La lógica del amor cristiano, que en el Evangelio es como el corazón palpitante del bien moral, llevado a sus últimas consecuencias, llega hasta el amor por los enemigos: "Si tu enemigo tiene hambre, dale de comer; $y$ si tiene sed, dale de beber" $(R m 12,20)$.

1 San Agustín afirma a este respecto: "Dos amores han dado origen a dos ciudades: el amor de sí mismo hasta el desprecio de Dios, la terrena; y el amor de Dios hasta el desprecio de sí mismo, la celestial" (De Civitate Dei, XIV, 28). 


\section{La "gramática" de la ley moral universal}

3 . Al contemplar la situación actual del mundo no se puede ignorar la impresionante proliferación de múltiples manifestaciones sociales y políticas del mal: desde el desorden social a la anarquía y a la guerra, desde la injusticia a la violencia y a la supresión del otro. Para orientar el propio camino frente a la opuesta atracción del bien y del mal, la familia humana necesita urgentemente tener en cuenta el patrimonio común de valores morales recibidos como don de Dios. Por eso, a cuantos están decididos a vencer al mal con el bien san Pablo los invita a fomentar actitudes nobles y desinteresadas de generosidad y de paz (cf. Rm 12,17-21).

Hace ya diez años, hablando a la Asamblea General de las Naciones Unidas sobre la tarea común al servicio de la paz, hice referencia a la "gramática" de la ley moral universal, ${ }^{2}$ recordada por la Iglesia en sus numerosos pronunciamientos sobre esta materia. Dicha ley une a los hombres entre sí inspirando valores y principios comunes, si bien en la diversidad de culturas, y es inmutable: "subsiste bajo el flujo de las ideas y costumbres y sostiene su progreso [...]. Incluso cuando se llega a renegar de sus principios, no se la puede destruir ni arrancar del corazón del hombre. Resurge siempre en la vida de individuos y sociedades". ${ }^{3}$

4. Esta común gramática de la ley moral exige un compromiso constante y responsable para que se respete y promueva la vida de las personas y los pueblos. A su luz no se puede dejar de reprobar con vigor los males de carácter social y político que afligen al mundo, sobre todo los provocados por los brotes de violencia. En este contexto, ¿cómo no pensar en el querido Continente africano donde persisten conflictos que han provocado y siguen provocando millones de víctimas? ¿Cómo no recordar la peligrosa situación de Palestina, la tierra de Jesús, donde no se consigue asegurar, en la verdad y en la justicia, las vías de la mutua comprensión, truncadas a causa de un conflicto alimentado cada día de manera preocupante por atentados y venganzas? Y, ¿qué decir del trágico fenómeno de la violencia terrorista que parece conducir al mundo entero hacia un futuro de miedo y angustia? En fin, ¿cómo no constatar con amargura que el drama iraquí se extiende por desgracia a situaciones de incertidumbre e inseguridad para todos?

2 Cf. Discurso para el $50^{\circ}$ aniversario de fundación de la ONU (5 octubre 1995), 3: Insegnamenti, XVIII, 2 (1995), 732.

3 Catecismo de la Iglesia Católica, n. 1958. 
Para conseguir el bien de la paz es preciso afirmar con lúcida convicción que la violencia es un mal inaceptable y que nunca soluciona los problemas. "La violencia es una mentira, porque va contra la verdad de nuestra fe, la verdad de nuestra humanidad. La violencia destruye lo que pretende defender: la dignidad, la vida, la libertad del ser humano". ${ }^{4}$ Por tanto, es indispensable promover una gran obra educativa de las conciencias, que forme a todos en el bien, especialmente a las nuevas generaciones, abriéndoles al horizonte del humanismo integral y solidario que la Iglesia indica y desea. Sobre esta base es posible dar vida a un orden social, económico y político que tenga en cuenta la dignidad, la libertad y los derechos fundamentales de cada persona.

\section{El bien de la paz y el bien común}

5. Para promover la paz, venciendo al mal con el bien, hay que tener muy en cuenta el bien común ${ }^{5}$ y sus consecuencias sociales y políticas. En efecto, cuando se promueve el bien común en todas sus dimensiones, se promueve la paz. ¿Acaso puede realizarse plenamente la persona prescindiendo de su naturaleza social, es decir, de su ser "con" y "para" los otros? El bien común le concierne muy directamente. Concierne a todas las formas en que se realiza su carácter social: la familia, los grupos, las asociaciones, las ciudades, las regiones, los Estados, las comunidades de pueblos y de Naciones. De alguna manera, todos están implicados en el trabajo por el bien común, en la búsqueda constante del bien ajeno como si fuera el propio. Dicha responsabilidad compete particularmente a la autoridad política, a cada una en su nivel, porque está llamada a crear el conjunto de condiciones sociales que consientan y favorezcan en los hombres y mujeres el desarrollo integral de sus personas. ${ }^{6}$

El bien común exige, por tanto, respeto y promoción de la persona y de sus derechos fundamentales, así como el respeto y promoción de los derechos de las Naciones en una perspectiva universal. Como dice el Concilio Vaticano II:

4 Homilía en Drogheda, Irlanda (29 septiembre 1979), 9: AAS 71 (1979), 1081.

5 Según una vasta acepción, por bien común se entiende "el conjunto de aquellas condiciones de vida social que permiten a los grupos y a cada uno de sus miembros conseguir más plena y fácilmente su propia perfección”: Conc. Ecum. Vat. II, Cons. past. Gaudium et spes, 26.

6 Cf. Juan XXIII, Enc. Mater et magistra: AAS 53 (1961), 417. 
"De la interdependencia cada vez más estrecha y extendida paulatinamente a todo el mundo se sigue que el bien común [...] se hace hoy cada vez más universal y por ello implica derechos y deberes que se refieren a todo el género humano. Por lo tanto, todo grupo debe tener en cuenta las necesidades y aspiraciones legítimas de los demás grupos; más aún, debe tener en cuenta el bien común de toda la familia humana". ${ }^{7}$ El bien de la humanidad entera, incluso el de las futuras generaciones, exige una verdadera cooperación internacional, con las aportaciones de cada Nación. ${ }^{8}$

Sin embargo, las concepciones claramente restrictivas de la realidad humana transforman el bien común en un simple bienestar socioeconómico, carente de toda referencia trascendente y vacío de su más profunda razón de ser. El bien común, en cambio, tiene también una dimensión trascendente, porque Dios es el fin último de sus criaturas. ${ }^{9}$ Además, los cristianos saben que Jesús ha iluminado plenamente la realización del verdadero bien común de la humanidad. Ésta camina hacia Cristo y en Él culmina la historia: gracias a Él, a través de Él y por Él, toda realidad humana puede llegar a su perfeccionamiento pleno en Dios.

\section{El bien de la paz y el uso de los bienes de la tierra}

6. Dado que el bien de la paz está unido estrechamente al desarrollo de todos los pueblos, es indispensable tener en cuenta las implicaciones éticas del uso de los bienes de la tierra. El Concilio Vaticano II ha recordado que "Dios ha destinado la tierra y todo cuanto ella contiene para uso de todos los hombres y pueblos, de modo que los bienes creados deben llegar a todos en forma equitativa bajo la guía de la justicia y el acompañamiento de la caridad". 10

La pertenencia a la familia humana otorga a cada persona una especie de ciudadanía mundial, haciéndola titular de derechos y deberes, dado que los hombres están unidos por un origen y supremo destino comunes. Basta que un niño sea concebido para que sea titular de derechos, merezca atención

\footnotetext{
7 Cons. past. Gaudium et spes, 26.

8 Cf. Juan XXIII, Enc. Mater et magistra: AAS 53 (1961), 421.

9 Cf. Enc. Centesimus annus, 41: AAS 83 (1991), 844.

10 Cons. past. Gaudium et spes, 69 .
} 
y cuidados, y que alguien deba proveer a ello. La condena del racismo, la tutela de las minorías, la asistencia a los prófugos y refugiados, la movilización de la solidaridad internacional para todos los necesitados, no son sino aplicaciones coherentes del principio de la ciudadanía mundial.

7. El bien de la paz se ha de considerar hoy en estrecha relación con los nuevos bienes provenientes del conocimiento científico y del progreso tecnológico. También éstos, aplicando el principio del destino universal de los bienes de la tierra, deben ser puestos al servicio de las necesidades primarias del hombre. Con iniciativas apropiadas de ámbito internacional se puede realizar el principio del destino universal de los bienes, asegurando a todos -individuos y Naciones- las condiciones básicas para participar en el desarrollo. Esto es posible si se prescinde de las barreras y los monopolios que dejan al margen a tantos pueblos. ${ }^{11}$

Además, se garantizará mejor el bien de la paz si la comunidad internacional se hace cargo, con mayor sentido de responsabilidad, de los comúnmente llamados bienes públicos. Se trata de aquellos bienes de los que todos los ciudadanos gozan automáticamente, aun sin haber hecho una opción precisa por ellos. Es lo que ocurre, por ejemplo, en el ámbito nacional, con bienes como el sistema judicial, la defensa y la red de carreteras o ferrocarriles. En el mundo de hoy, tan afectado por el fenómeno de la globalización, son cada vez más numerosos los bienes públicos que tienen un carácter global $\mathrm{y}$, consecuentemente, aumentan también de día en día los intereses comunes. Baste pensar en la lucha contra la pobreza, la búsqueda de la paz y la seguridad, la preocupación por los cambios climáticos, el control de la difusión de las enfermedades. La comunidad internacional tiene que responder a estos intereses con un red cada vez más amplia de acuerdos jurídicos que reglamenten el uso de los bienes públicos, inspirándose en los principios universales de la equidad y la solidaridad.

8. El principio del destino universal de los bienes permite, además, afrontar adecuadamente el desafío de la pobreza, sobre todo teniendo en cuenta las condiciones de miseria en que viven aún más de mil millones de seres humanos. La comunidad internacional se ha puesto como objetivo prioritario, al principio del nuevo milenio, reducir a la mitad el número de dichas personas antes de terminar el año 2015. La Iglesia apoya y anima este compromiso e invita a los creyentes en Cristo a manifestar, de modo concreto y en todos

11 Cf. Enc. Centesimus annus, 35: AAS 80 (1988), 837. 
los ámbitos, un amor preferencial por los pobres. ${ }^{12}$

El drama de la pobreza está en estrecha conexión con el problema de la deuda externa de los Países pobres. A pesar de los logros significativos conseguidos hasta ahora, la cuestión no ha encontrado todavía una solución adecuada. Han pasado quince años desde que llamé la atención de la opinión pública sobre el hecho de que la deuda externa de los Países pobres está "conectada con un gran número de otros temas, como el de las inversiones en el extranjero, el trabajo equitativo de las principales instituciones internacionales, el precio de las materias primas, etc.". ${ }^{13}$ Las recientes medidas para reducir las deudas, que han tenido más en cuenta las exigencias de los pobres, han mejorado sin duda la calidad del crecimiento económico. No obstante, por una serie de factores, dicho crecimiento resulta todavía insuficiente cuantitativamente, especialmente para alcanzar los objetivos propuestos al inicio del milenio. Los Países pobres se encuentran aún en un círculo vicioso: las rentas bajas y el crecimiento lento limitan el ahorro y, a su vez, las reducidas inversiones y el uso ineficaz del ahorro no favorecen el crecimiento.

9. Como afirmó el Papa Pablo VI, y como yo mismo he recordado, el único remedio verdaderamente eficaz para permitir a los Estados afrontar la dramática cuestión de la pobreza es dotarles de los recursos necesarios mediante financiaciones externas -públicas y privadas-, otorgadas en condiciones accesibles, en el marco de las relaciones comerciales internacionales, reguladas de manera equitativa. ${ }^{14} \mathrm{Es}$, pues, necesaria una movilización moral y económica, que respete los acuerdos tomados en favor de los Países pobres, por un lado, y por otro dispuesta también a revisar dichos acuerdos cuando la experiencia demuestre que son demasiado gravosos para ciertos países. En esta perspectiva, es deseable y necesario dar un nuevo impulso a la ayuda pública para el desarrollo y, no obstante las dificultades que puedan presentarse, estudiar las propuestas de nuevas formas de financiación para el desarrollo. ${ }^{15}$ Algunos gobiernos están considerando atentamente medidas esperanzadoras en este sentido, iniciativas significativas que se han de llevar

12 Cf. Enc. Sollicitudo rei socialis, 42: AAS 80 (1988), 572.

13 Discurso a los participantes en la Semana de Estudios organizada por la Pontificia Academia de las Ciencias (27 octubre 1989), 6: Insegnamenti XII/2 (1989), 1050.

14 Cf. Pablo VI, Enc. Populorum progressio, 56-61: AAS 59 (1967), 285- 287; Juan Pablo II, Enc. Sollicitudo rei socialis, 33-34: AAS 80 (1988) 557-560.

15 Cf. Mensaje al Presidente del Consejo Pontificio "Justicia y Paz": L'Osservatore Romano, ed. semanal en lengua española (16 julio 2004), p. 3. 
adelante de modo multilateral y respetando el principio de subsidiaridad. Es necesario también controlar que la gestión de los recursos económicos destinados al desarrollo de los Países pobres siga criterios escrupulosos de buena administración, tanto por parte de los donantes como de los destinatarios. La Iglesia alienta estos esfuerzos y ofrece su contribución. Baste citar, por ejemplo, la valiosa aportación que dan las numerosas agencias católicas de ayuda y de desarrollo.

10. Al finalizar el Gran Jubileo del año 2000, en la Carta apostólica Novo millennio ineunte he señalado la urgencia de una nueva imaginación de la caridad ${ }^{16}$ para difundir en el mundo el Evangelio de la esperanza. Eso se hace evidente sobre todo cuando se abordan los muchos y delicados problemas que obstaculizan el desarrollo del Continente africano: piénsese en los numerosos conflictos armados, en las enfermedades pandémicas, más peligrosas aún por las condiciones de miseria, en la inestabilidad política unida a una difusa inseguridad social. Son realidades dramáticas que reclaman un camino radicalmente nuevo para África: es necesario dar vida a nuevas formas de solidaridad, bilaterales y multilaterales, con un mayor compromiso por parte de todos y tomando plena conciencia de que el bien de los pueblos africanos representa una condición indispensable para lograr el bien común universal.

Es de desear que los pueblos africanos asuman como protagonistas su propia suerte y el propio desarrollo cultural, civil, social y económico. Que África deje de ser sólo objeto de asistencia, para ser sujeto responsable de un modo de compartir real y productivo. Para alcanzar tales objetivos es necesaria una nueva cultura política, especialmente en el ámbito de la cooperación internacional. Quisiera recordar una vez más que el incumplimiento de las reiteradas promesas relativas a la ayuda pública para el desarrollo y la cuestión abierta aún de la pesada carga de la deuda internacional de los Países africanos y la carencia de una consideración especial con ellos en las relaciones comerciales internacionales, son graves obstáculos para la paz, y por tanto deben ser afrontados y superados con urgencia. Para lograr la paz en el mundo es determinante y decisivo, hoy más que nunca, tomar conciencia de la interdependencia entre Países ricos y pobres, por lo que "el desarrollo o se convierte en un hecho común a todas las partes del mundo, o sufre un proceso de retroceso aún en las zonas marcadas por un constante progreso". ${ }^{17}$

16 Cf. n. 50: $A A S 93$ (2001), 303.

17 Enc. Sollicitudo rei socialis, 17: AAS 80 (1988), 532. 


\section{Universalidad del mal y esperanza cristiana}

11. Ante tantos dramas como afligen al mundo, los cristianos confiesan con humilde confianza que sólo Dios da al hombre y a los pueblos la posibilidad de superar el mal para alcanzar el bien. Con su muerte y resurrección, Cristo nos ha redimido y rescatado pagando "un precio muy alto" (cf. 1 Co $6,20 ; 7,23)$, obteniendo la salvación para todos. Por tanto, con su ayuda todos pueden vencer al mal con el bien.

Con la certeza de que el mal no prevalecerá, el cristiano cultiva una esperanza indómita que lo ayuda a promover la justicia y la paz. A pesar de los pecados personales y sociales que condicionan la actuación humana, la esperanza da siempre nuevo impulso al compromiso por la justicia y la paz, junto con una firme confianza en la posibilidad de construir un mundo mejor.

Si es cierto que existe y actúa en el mundo el "misterio de la impiedad" (2 $T s$, 27), no se debe olvidar que el hombre redimido tiene energías suficientes para afrontarlo. Creado a imagen de Dios y redimido por Cristo que "se ha unido, en cierto modo, con todo hombre", ${ }^{18}$ éste puede cooperar activamente a que triunfe el bien. La acción del "espíritu del Señor llena la tierra" ( $S b$ 1,7). Los cristianos, especialmente los fieles laicos, "no pueden esconder esta esperanza simplemente dentro de sí. Tienen que manifestarla incluso en las estructuras del mundo por medio de la conversión continua y de la lucha "contra los poderes de este mundo de tinieblas, contra los espíritus del mal" $(E f 6,12)$ ". ${ }^{19}$

12. Ningún hombre, ninguna mujer de buena voluntad puede eximirse del esfuerzo en la lucha para vencer al mal con el bien. Es una lucha que se combate eficazmente sólo con las armas del amor. Cuando el bien vence al mal, reina el amor y donde reina el amor reina la paz. Es la enseñanza del Evangelio, recordada por el Concilio Vaticano II: "La ley fundamental de la perfección humana, y por ello de la transformación del mundo, es el mandamiento nuevo del amor". ${ }^{20}$

Esto también es verdad en el ámbito social y político. A este respecto, el Papa León XIII escribió que quienes tienen el deber de proveer al bien de la paz en las relaciones entre los pueblos han de alimentar en sí mismos e

18 Conc. Ecum. Vat. II, Cons. past. Gaudium et spes, 22.

19 Conc. Ecum. Vat. II, Const. dogm. Lumen gentium, 35.

20 Cons. past. Gaudium et spes, 38. 
infundir en los demás "la caridad, señora y reina de todas las virtudes". ${ }^{21}$ Los cristianos han de ser testigos convencidos de esta verdad; han de saber mostrar con su vida que el amor es la única fuerza capaz de llevar a la perfección personal y social, el único dinamismo posible para hacer avanzar la historia hacia el bien y la paz.

En este año dedicado a la Eucaristía, los hijos de la Iglesia han de encontrar en el Sacramento supremo del amor la fuente de toda comunión: comunión con Jesús Redentor y, en Él, con todo ser humano. En virtud de la muerte y resurrección de Cristo, sacramentalmente presentes en cada Celebración eucarística, somos rescatados del mal y capacitados para hacer el bien. Gracias a la vida nueva que Él nos ha dado, podemos reconocernos como hermanos, por encima de cualquier diferencia de lengua, nacionalidad o cultura. En una palabra, por la participación en el mismo Pan y el mismo Cáliz, podemos sentirnos "familia de Dios" y al mismo tiempo contribuir de manera concreta y eficaz a la edificación de un mundo fundado en los valores de la justicia, la libertad y la paz.

Vaticano, 8 de diciembre de 2004.

21 Enc. Rerum novarum: Acta Leonis XIII, 11 (1892), 143; cf. Benedicto XV, Enc. Pacem Dei: AAS 12 (1920), 215. 